\title{
PENGARUH FAKTOR PRODUKSI TERHADAP PENGEMBANGAN PERIKANAN TUNA DI KOTA AMBON
}

\section{(THE PRODUCTION FACTORS INFLUENCE OF TUNA FISHING DEVELOPMENT IN AMBON CITY')}

\author{
Selfi Sangadji ${ }^{12}$, Mustaruddin ${ }^{2}$, Sugeng Hari Wisudo ${ }^{2}$ \\ ${ }^{1}$ Corresponding author \\ 2 Departemen Pemanfaatan Sumberdaya Perairan \\ Fakultas Perikanan dan Ilmu Kelautan, Institut Pertanian Bogor \\ E-mail: selfi_sangadji@yahoo.co.id
}

\begin{abstract}
The purpose of the study is to analyze the influence level of the production factors to development of the tuna fishing industry in Ambon City. The data collected are the vessel size, gear size, long trip, fuel use, ice use, fresh water and the number of crew. The data comes from Ambon tuna fishermen. Data collected are primary and secondary data. The analysis used is multiple regression analysis. Multiple regression analysis of the relationship of tuna production gets the value of significance (sig) 0,000. Sig be in the range of beliefs $<0.005$ means that the regression model can predict the tuna fishery production. Determinant coefficient (R2) of about 0.719 shows the influence of production factors together could explain $71.9 \%$ up and down the production of tuna. Base on the significance value of each production factor to production, only the use BBM (X4) and the use of ice cubes (X5) which has a significance value $<0.05$ (0.000). Use of X5 is influential but has no effect supports the development of tuna in Ambon City. Conclusions taken from this study is the production of factors that influence the production of tuna fisheries in Ambon is the use BBM and the use of ice cubes (X5) which has a significance value $<0.05$ is 0.000 .
\end{abstract}

Keywords: Production factors, tuna industry development

\begin{abstract}
ABSTRAK
Tujuan penelitian yaitu menganalisis tingkat pengaruh faktor produksi terhadap pengembangan industri perikanan tuna di Kota Ambon. Data yang dikumpulkan terdiri dari data primer dan data sekunder. Data yang dikumpulkan yaitu ukuran kapal, ukuran alat tangkap, lama trip, pegggunaan BBM, pengunaan es, air tawar dan jumlah ABK. Data berasal dari nelayan tuna Kota Ambon. Analisis yang digunakan adalah analisis regresi berganda. Hasil analisis regresi berganda tentang hubungan produksi ikan tuna mendapat nilai signifikansi (sig) 0,000. Nilai sig berada dalam range kepercayaan $<0,005$ berarti model regersi ini dapat memprediksi produksi perikanan tuna. Koefisien determinan (R2) sekitar 0,719 menunjukan pengaruh bersama-sama faktor produksi dapat menjelaskan $71,9 \%$ naik turun produksi tuna. Bila melihat nilai signifikansi setiap faktor produksi terhadap produksi, maka hanya penggunaan BBM (X4) dan penggunaan es balok (X5) yang mempunyai nilai signifikansi $<0,05$ (0,000). Penggunaan BBM memang berpengaruh tetapi tidak berpengaruh mendukung perkembangan tuna di Kota Ambon. Kesimpulan yang di ambil dari penelitian ini adalah faktor produksi yang sangat mempengaruhi produksi perikanan tuna di Kota Ambon adalah penggunaan BBM dan penggunaan es balok yang mempunyai nilai signifikansi $<0,05$ yaitu 0,000 .
\end{abstract}

Kata Kunci: Faktor produksi, pengembangan industri tuna

\section{Pendahuluan}

Laut Maluku merupakan daerah penangkapan tuna yang baik, karena perairan tersebut berada di antara pulau-pulau yang memungkinkan terjadinya upwelling. Pada perairan laut ini juga tertangkap ikan tuna berukuran besar dengan bobot rata-rata 50 hingga $230 \mathrm{~kg}$ (Khoirul et al, 2012).

Pembangunan perikanan yang telah dilaksanakan selama ini, telah menunjukkan hasil yang cukup baik. Hal ini dapat dilihat dari semakin luas dan terarahnya usaha peningkatan produksi perikanan yang pada akhirnya dapat meningkatkan pula konsumsi ikan, ekspor hasil perikanan, pendapatan nelayan, memperluas lapangan kerja, memberikan dukungan terhadap pembangunan bidang industri dan menunjang pembangunan daerah. Peningkatan produksi perikanan terutama didukung oleh meningkatnya produksi perikanan tangkap (fishing), yang memberikan sumbangan 
terbesar yaitu sebesar 75\% dari total produksi perikanan (Nikijuluw, 2002).

Berkembangnya aktifitas penangkapan ikan, telah terjadi peningkatan produksi perikanan laut sebesar ratarata $5 \%$ per tahun. Produksi tersebut masih bisa ditingkatkan lagi dengan cara mengembangkan armada penangkapan, memperluas daerah penangkapan dan meningkatkan teknologinya. Peningkatan produksi dimungkinkan untuk dilakukan, mengingat Indonesia memiliki wilayah perairan laut seluas sekitar 3.1 juta kilometer persegi, yang terdiri dari 0.3 juta kilometer persegi perairan teritorial dan 2.8 juta kilometer persegi perairan nusantara. Disamping itu Indonesia mempunyai kewenangan untuk mengelola Wilayah Zona Ekonomi Eksklusif Indonesia (ZEEI) seluas 2.7 juta kilometer persegi. Seluruh wilayah perairan tersebut menyediakan potensi sumberdaya hayati sebesar 6.7 juta ton per tahun dan tingkat pemanfaatannya baru sebesar 48\% (Dahuri et al, 2001).

Kota Ambon terletak di bagian selatan Pulau Ambon, tepatnya di daerah pesisir Teluk Ambon dan Teluk Baguala. Total luas wilayah Kota Ambon sekitar $786 \mathrm{~km}^{2}$, terbagi atas luas daratan 377 $\mathrm{km}^{2}(48 \%)$ sedangkan luas perairan $4 \mathrm{mil}$ laut sebesar $409.0 \quad \mathrm{~km}^{2} \quad(52 \%)$. Luas daratan Kota Ambon ini hampir separuh dari luas Pulau Ambon dengan garis pantai sepanjang $102.7 \mathrm{~km}$.

Dari segi ekonomi, Kota Ambon mengalami perkembangan yang cukup pesat, melebihi kabupaten atau kota lainnya di Maluku. Hal ini dapat dilihat dari rata-rata pertumbuhan ekonomi setiap tahun dalam lima tahun, berkisar $5.5 \%$ - 7\%, sedangkan kabupaten atau kota lain di Maluku rata-rata kurang dari $5 \%$ per tahun. Dari segi struktur ekonomi, perekonomian Kota Ambon dalam tiga tahun terakhir (2008-2010) didominasi 3 sektor primer yang memberi kontribusi tertinggi terhadap PDRB, yaitu:

1) Sektor perdagangan dengan kontribusi rata-rata per tahun 28\% dengan pertumbuhan yang relatif stabil sekitar 6\% per tahun,

2) Sektor pemerintahan umum dan pertahanan dengan kontribusi rata-rata per tahun $22 \%$ dengan pertumbuhan yang relatif stabil sekitar 6\% per tahun,
3) Sektor perikanan dengan kontribusi rata-rata per tahun $17 \%$, dengan pertumbuhan yang relatif stabil sekitar $4.5 \%$ per tahun.

Kontribusi sektor lainnya terhadap PDRB Kota Ambon rata-rata dibawah 6\%. Data di atas menunjukkan bahwa sektor perikanan merupakan salah satu sektor andalan bagi perekonomian di Kota Ambon. Dengan demikian, sebagai kota pesisir yang memiliki wilayah laut dan dikelilingi oleh laut yang potensial, perikanan dan jasa kelautan dapat menjadi salah satu kontributor penting dalam upaya untuk meningkatkan kesejahteraan masyarakat, terutama masyarakat yang tinggal di wilayah pesisir. Untuk itu, sektor perikanan dapat dikembangkan secara maksimal, dan menjadi andalan bagi pengembangan ekonomi di Kota Ambon.

Wilayah perairan Kota Ambon memiliki sumberdaya perikanan yang sangat potensial ditinjau dari besaran stok maupun peluang pemanfaatan dan pengembangannya. Hal ini dapat dilihat dari hasil penelitian dan analisis terhadap kelimpahan stok potensi lestari. Untuk jenis ikan pelagis kecil kelimpahan stoknya adalah sebesar 1470.7 ton/bulan dengan potensi lestari sebesar 735.4 ton/bulan. Jenis-jenis ikan pelagis kecil yang memiliki potensi untuk dimanfaatkan dan dikembangkan adalah Stolephorus spp, Sardinela spp, Decapterus spp, Restrelliger spp serta Cypselurus spp. Ikan pelagis besar tersebar pada wilayah ekologis pantai selatan Kota Ambon dengan kelimpahan stok sebesar 620.6 ton/bln dengan maksimum tangkap lestari (MSY) sebesar 310.3 ton/bulan. Ikan pelagis besar didominasi oleh Cakalang (Skipjack Tuna) dan Tatihu (Yellow Fin Tuna) (Dinas kelautan dan perikanan Kota Ambon, 2012).

Produksi perikanan mempunyai peran yang sangat penting dalam pengembangan ekonomi maupun sosial. Permintaan terhadap produk-produk laut semakin hari semakin meningkat mengakibatkan terjadinya perdagangan yang semakin besar guna memenuhi kebutuhan pasar tersebut. Untuk memenuhi kebutuhan pasar tersebut maka perlu ada peningkatan jumlah operasi penangkapan.

Keberhasilan operasi penangkapan ikan dipengaruhi oleh banyak faktor 
diantaranya adalah alat tangkapnya sendiri, kapal, alat bantu serta sumberdaya manusia yang mengoperasikannya. Sumberdaya manusia yang handal juga sangat diperlukan dalam keberhasilan penangkapan ikan. Ketepatan analisa dalam penentuan fishing ground dan ketrampilan dalam manajemen kegiatan di kapal (Direktorat Jenderal Perikanan Tangkap, 2004)

Pengembangan suatu industri perikanan tuna sangat bergantung pada produksi hasil tangkapan nelayan. Jumlah produksi perikanan dapat bertambah dilihat dari beberapa faktor yang dapat mendukung terlaksananya suatu kegiatan penangkapan. Oleh karena itu, untuk menghasilkan suatu produk, maka diperlukan pengetahuan hubungan antara faktor produksi dan output produksi (Soekartawi, 2002). Ketidaksiapan faktor produksi dapat menyebabkan kegiatan operasi penangkapan tidak dapat berjalan lancar.

Produksi adalah hasil produksi dari hasil usaha penangkapan dengan alat tangkap pancing tonda. Data yang digunakan adalah data yang diambil pada setiap satu trip penangkapan untuk data harian. Faktor-faktor produksi yang sangat berpengaruh dalam penangkapan tuna adalah ukuran kapal, ukuran alat tangkap, lama trip, pegggunaan BBM, pengunaan es, air tawar dan jumlah ABK. Ukuran kapal adalah bobot kapal kotor yang dinyatakan dalam Gross Tonnage (GT). Ukuran alat tangkap adalah panjang tali yang digunakan (m). Penggunaan BBM adalah jumlah bahan bakar yang digunakan oleh nelayan tuna untuk melaut (liter). Penggunaan es adalah jumlah es yang digunakan dalam penanganan hasil tangkapan di atas kapal (balok). Jumlah ABK adalah jumlah awak yang membantu nelayan dalam proses penangkapan (orang).

Untuk mengetahui faktor-faktor apa saja yang berpengaruh terhadap pengembangan perikanan tuna di Kota Ambon, perlu diadakan suatu kajian untuk mengetahui faktor-faktor yang berperan dalam pengembangan perikanan tuna di Kota Ambon. Dengan mengetahui faktorfaktor tersebut diharapkan dapat mengembangkan perikanan tuna dengan optimal.

\subsection{Tujuan}

Menentukan faktor produksi yang berpengaruh signifikan terhadap pengembangan perikanan tuna di Kota Ambon.

\subsection{Manfaat}

a) Bahan informasi bagi pengelola usaha perikanan tuna dalam mengembangkan usahanya.

b) Bahan masukan bagi pemerintah daerah dalam pengambilan kebijakan dalam pengembangan perikanan tuna di Kota Ambon.

\section{METODE PENELITIAN}

\subsection{Waktu dan Lokasi Penelitian}

Penelitian dilaksanakan pada bulan Januari hingga bulan April 2013 bertempat di Desa Laha, Desa Latuhalat dan Desa Seri, Kota Ambon, Provinsi Maluku.

\subsection{Bahan dan Alat}

Bahan dan alat yang digunakan dalam penelitian ini adalah quisioner, alat tulis-menulis, dan kamera sebagai publikasi.

\subsection{Jenis dan sumber data}

Data yang dikumpulkan terdiri dari data primer dan data sekunder. Data primer terdiri dari ukuran kapal, ukuran alat tangkap, lama trip, penggunaan bahan bakar minyak (BBM), penggunaan es, air tawar dan jumlah anak buah kapal (ABK), sedangkan untuk data sekunder yang diambil adalah data produksi perikanan tuna kota Ambon. Sumber data primer dari 3 desa nelayan yang berada di wilayah Kota Ambon, yakni: Desa Latuhalat, Desa Seri dan Desa Laha, sedangkan sumber data sekunder dari Dinas Perikanan Kotamadya Ambon.

\subsection{Metode pengumpulan data}

Metode yang dipakai dalam penelitian ini adalah: 1) Metode Penelaan Studi literatur untuk mendapatkan informasi dari studi sebelumnya yang terkait dengan penelitian yang dilakukan; 2) Metode wawancara dengan menggunakan kuesioner, metode ini langsung dilakukan kepada nelayan yang berada di tiga lokasi yang berbeda yakni: Desa Laha, Desa Seri dan Desa Latuhalat dengan jumlah responden 60 orang, masing-masing desa 20 responden, pemi- 
lihan responden dilakukan secara purposive: 3) Metode pengamatan langsung, dilakukan untuk mengetahui secara langsung aktivitas penangkapan ikan yang dilakukan oleh para nelayan.

\subsection{Analisis data}

Sebelum mengetahui faktor-faktor yang berpengaruh terhadap produksi perikanan tuna, harus mengetahui faktor-faktor tersebut saling bebas satu sama lain dengan uji multikolinearitas. Salah satu dari asumsi model regresi linear klasik adalah bahwa tidak terdapat multikolinearitas diantara variabel yang menjelaskan yang termasuk dalam model. Menurut Gujarati (1995) multikolinearitas berarti adanya hubungan yang sempurna atau pasti diantara beberapa atau semua.

Cara mendeteksi ada tidaknya multikolinearitas adalah dengan melihat hasil matrix korelasi dimana menurut Ghozali (2001), bila ada korelasi yang cukup tinggi antar variabel bebas (umumnya di atas 0.90) maka hal ini merupakan indikasi adanya multikolinearitas. Tidak adanya korelasi yang tinggi antar variabel bebas tidak berarti bebas dari multikolinearitas. Multikolinearitas dapat disebabkan karena adanya efek kombinasi dua atau lebih variabel bebas.

Untuk menganalisis tingkat pengaruh faktor produksi terhadap pengembangan perikanan tuna di Kota Ambon analisis yang digunakan adalah analisis regresi berganda logaritmik. Analisis regresi berganda ini dilakukan untuk mengetahui jenis-jenis faktor produksi yang penting dan signifikan mendukung operasi usaha perikanan tuna di Kota Ambon. Hal ini dilakukan dengan membangun persamaan dengan pendekatan matematis dari analisis regresi berganda. Menurut Sarwono (2006), analisis regresi berganda dapat dikembangkan lanjut menggunakan pendekatan kurva untuk mengetahui pola yang lebih tepat dari atau hubungan apakah murni linear, kuadratik, logaritmik maupun sigmoid. Untuk menguji pengaruh variabel bebas $\left(\mathrm{X}_{1}, \mathrm{X}_{2}, \mathrm{X}_{3}, \ldots, \mathrm{X}_{5}\right)$ secara individu terhadap variabel terikat (Y). Uji statistik yang digunakan adalah $\mathrm{Uji} t$ dengan rumus sebagai berikut (Sudjana, 2002):

$t_{\text {hitung }}=\frac{a_{i}}{S a_{i}}$
Dimana :

$\mathrm{a}_{\mathrm{i}}=$ Koefisien Regresi Variabel $\mathrm{X}_{\mathrm{i}}(\mathrm{i}=1,2$, $3, \ldots, 5)$

$\mathrm{Sa}_{\mathrm{i}}=$ Standar Error Variabel $\mathrm{X}_{\mathrm{i}}(\mathrm{i}=1,2$, $3, \ldots, 5)$ berikut:

Dengan kaedah keputusan sebagai

Bila $\mathrm{t}_{\text {hitung }}<\mathrm{t}$ Tabel atau P-value $(\mathrm{a}=0,05)$, maka tolak Ha.

Bila $t_{\text {hitung }}>\mathrm{t}$ Tabel atau P-value $(\mathrm{a}=0,05)$, maka terima Ha.

Dimana hipotesis:

Ho : $\mathrm{a}_{\mathrm{i}}=\mathrm{o}$, Variabel bebas $\left(\mathrm{X}_{1}, \mathrm{X}_{2}, \mathrm{X}_{3}, \ldots\right.$, $\mathrm{X}_{5}$ ) berpengaruh tidak nyata terhadap variabel terikat $Y$.

Ha : $a_{i} \neq 0$, Variabel bebas $\left(X_{1}, X_{2}, X_{3}, \ldots\right.$, $\left.\mathrm{X}_{5}\right)$ berpengaruh nyata terhadap variabel terikat.

Dalam analisis ini, yang merupakan variabel tetap adalah produksi (Y), dan variabel bebasnya adalah ukuran kapal $\left(\mathrm{X}_{1}\right)$, ukuran alat tangkap $\left(\mathrm{X}_{2}\right)$, penggunaan $\mathrm{BBM}\left(\mathrm{X}_{3}\right)$, penggunaan es balok $\left(\mathrm{X}_{4}\right)$, Jumah ABK $\left(\mathrm{X}_{5}\right)$. Hubungan antara variabel-variabel tersebut dapat dirumuskan dalam bentuk persamaan:

$$
\mathrm{Y}=\mathrm{a}+\mathrm{b}_{1} \mathrm{X}_{1}+\mathrm{b}_{2} \mathrm{X}_{2}+\mathrm{b}_{3} \mathrm{X}_{3}+\ldots+\mathrm{b}_{5} \mathrm{X}_{5}
$$

Keterangan:

$\mathrm{Y}=$ Produksi

$\mathrm{a}=$ Konstanta

$\mathrm{X}_{1}=$ Ukuran kapal (GT)

$\mathrm{b}_{1}=$ Konstanta ukuran kapal

$\mathrm{X}_{2}=$ Ukuran alat tangkap (m)

$\mathrm{b}_{2}=$ Konstanta ukuran alat tangkap

$\mathrm{X}_{3}=$ Penggunaan BBM (Liter)

$\mathrm{b}_{3}=$ Konstanta penggunaan BBM

$\mathrm{X}_{4}=$ Penggunaan es (Balok)

$\mathrm{b}_{4}=$ Konstanta penggunaan es

$\mathrm{X}_{5}=$ Jumlah ABK (orang)

$\mathrm{b}_{5}=$ Konstanta jumlah ABK

\section{HASIL PENELITIAN}

\subsection{Perikanan Pancing Tonda Di Kota Ambon}

Perikanan tuna di Kota Ambon berpusat pada 3 daerah yaitu Desa Latuhalat, Desa Seri dan Desa Laha. Alat penangkapan yang digunakan untuk menangkap ikan tuna adalah pancing tonda (Tabel 1). Pancing tonda yang digunakan di Kota Ambon pada prinsipnya sama dengan pancing tonda yang digunakan di daerah lain, yang terdiri dari kapal penangkap ikan (Gambar 1) dan alat tangkap pancing. 
Pancing tonda berpotensi untuk dikembangkan di perairan Maluku setelah dianalisis berdasarkan aspek berkelanjutan sumberdaya ikan serta pemanfaatannya. Hasil tangkapan alat ini adalah jenis ikan pelagis besar seperti: ikan tuna, cakalang, tongkol dan tenggiri. Jenis-jenis ikan hasil tangkapan alat ini merupakan jenis-jenis ikan ekspor yang permintaannya di pasar internasional cukup besar, sehingga perlu dikelola dan dikembangkan guna menambah devisa daerah maupun negara. (Nanlohy, 2013).

Nelayan tuna di Kota Ambon biasanya melakukan operasi penangkapan ikan antar 7 sampai 11 jam, dengan lama trip 1 hari. Peralatan navigasi yang biasa digunakan adalah kompas, teleskop, GPS, Fishfinder, dan alat komunikasi berupa telepon genggam. Nelayannelayan di Kota Ambon melakukan penangkapan setiap musim, tapi biasanya pada musim peralihan hasil penangkapan banyak. Musim peralihan yaitu bulan Maret dan April, pada 2 bulan ini puncak penangkapan ikan tuna. Jenis tuna yang sering tertangkap di Kota Ambon yaitu jenis tuna mata besar (Big Eye Tuna) dan tuna sirip kuning (Yellow Fin Tuna).

\subsection{Pengaruh Faktor Produksi terhadap Perikanan Tuna di Kota Ambon}

Produksi nelayan rata-rata setiap tahunnya meningkat ditahun 2011 volume produksi perikanan tangkap Kota Ambon sebesar 1769.24 ton. Untuk mendukung suatu produksi diperlukan kesiapan faktor-faktor produksi sehingga operasi penangkapan dapat berjalan dengan lancar. Untuk melihat faktorfaktor apa saja yang berpengaruh dalam operasi perikanan tuna di Kota Ambon maka dilakukan perhitungan melalui analisis regresi berganda.

Terdapat 5 faktor yang mendukung dalam operasi penangkapan ikan tuna di Kota Ambon yaitu ukuran kapal, ukuran alat tangkap, penggunaan BBM, penggunaan es dan jumlah ABK. Yang digunakan untuk menguji ada tidaknya multikolinearitas dalam penelitian ini adalah dengan melihat matrix korelasi. Hasil yang ditunjukan oleh matrix korelasi dari regresi yang dilakukan adalah korelasi antara variabel bebas dibawah 0.9 sehingga dapat dikatakan tidak terdapat multikolinearitas.

Tabel 1. Spesifikasi Pancing Tonda

\begin{tabular}{clcc}
\hline \multirow{2}{*}{ No. } & \multicolumn{1}{c}{ SPESIFIKASI } & \multicolumn{2}{c}{ Ukuran Kapal } \\
\cline { 2 - 4 } & & $2 \mathrm{GT}^{*}$ & $3 \mathrm{GT}^{*}$ \\
\hline 1 & Panjang (m) & 9 & 10.5 \\
2 & Lebar (m) & 1.19 & 1.5 \\
3 & Tinggi (m) & 0.75 & 0.75 \\
4 & Ukuran Mesin (PK) & 40 & 15 \\
5 & Jumlah Bahan Bakar (liter) & 100 & 200 \\
6 & Jumlah ABK (orang) & 1 & 2 \\
7 & Jumlah Es (Balok) & 1 & 2 \\
8 & Jumlah Air Tawar (liter) & 5 & 5 \\
9 & Panjang Alat tangkap (m) & 400 & 600 \\
\hline${ }^{*}$ GT: Gross Tonnage & &
\end{tabular}

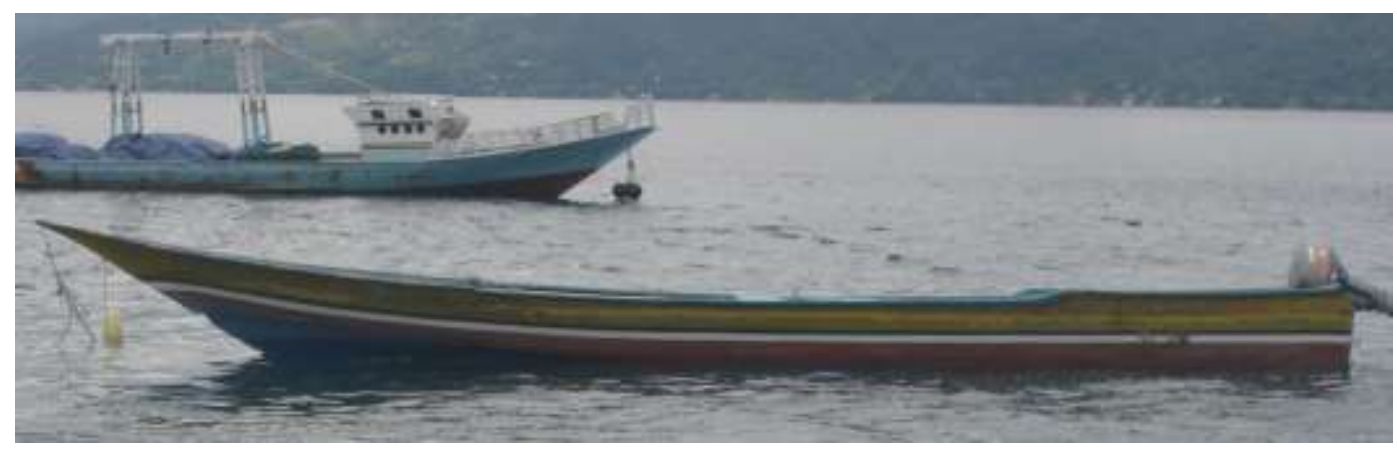

Gambar 1. Kapal Pancing Tonda 
Hasil analisis regresi berganda yang ditunjukan pada Tabel 2 tentang hubungan produksi ikan tuna mempunyai nilai signifikansi (sig) 0,000 . Nilai sig itu berada dalam selang kepercayaan < 0,005 itu berarti model regersi ini dapat memprediksi produksi perikanan tuna.

Berdasarkan Tabel 3, maka model hubungan antara produksi ikan tuna $(\mathrm{Y})$ dengan ukuran kapal $\left(\mathrm{X}_{1}\right)$, ukuran alat tangkap $\left(\mathrm{X}_{2}\right)$, penggunaan $\mathrm{BBM}\left(\mathrm{X}_{3}\right)$, penggunaan es balok $\left(\mathrm{X}_{4}\right)$, Jumah ABK $\left(\mathrm{X}_{5}\right)$ dapat diilustrasikan sebagai berikut:

$\mathrm{Y}=92.652+27.042 \mathrm{X} 1-0,026 \mathrm{X} 2-$ $3.405 \times 3+273.742 \times 4+6.741 X 5$

Model hubungan tersebut mempunyai koefisien determinan (R2) sebesar 0,719. Hal ini menunjukan bahwa pengaruh bersama-sama ukuran kapal
$\left(\mathrm{X}_{1}\right)$, ukuran alat tangkap $\left(\mathrm{X}_{2}\right)$, penggunaan BBM $\left(\mathrm{X}_{3}\right)$, penggunaan es balok $\left(\mathrm{X}_{4}\right)$, dan Jumah ABK (X5) dapat menjelaskan $71.9 \%$ naik turun produksi tuna. Sedangkan sisanya dipengaruhi faktor lain diluar yang dikaji. Bila melihat nilai signifikansi setiap faktor produksi terhadap prouksi ikan tuna di Kota Ambon, maka hanya penggunaan BBM (X3) dan penggunaan es balok (X4) yang mempunyai nilai signifikansi $<0.05$ (0.000), sedangkan ketiga faktor produksi lainnya > 0.05. Hal ini menunjukan bahwa hanya penggunaan BBM dan penggunaan es balok yang benar-benar nyata berpengaruh dalam kegiatan produksi ikan tuna di Kota Ambon. Tiga faktor produksi lainnya tidak menyebabkan perubahan nyata terhadap kegiatan ikan tuna di Kota Ambon.

Tabel 2. Hubungan produksi ikan tuna

ANOVA $^{\mathrm{b}}$

\begin{tabular}{llrrrrr}
\hline & Model & $\begin{array}{c}\text { Sum of } \\
\text { Squares }\end{array}$ & df & Mean Square & F & Sig. \\
\hline 1 & Regression & 1707022.915 & 5 & 341404.583 & 27.596 & $.000^{a}$ \\
& Residual & 668061.019 & 54 & 12371.500 & & \\
& Total & 2375083.933 & 59 & & & \\
\multicolumn{6}{l}{ Keterangan: Constant $:$ X5, X2, X1, X3, X4 } \\
\\
Dependent Variable $: \mathrm{Y}$
\end{tabular}

Tabel 3. Pengaruh faktor produksi terhadap operasi penangkapan ikan tuna

Coefficients $^{\mathrm{a}}$

\begin{tabular}{llrrrrr}
\hline \multirow{2}{*}{ Model } & \multicolumn{2}{c}{$\begin{array}{l}\text { Unstandardized } \\
\text { Coefficients }\end{array}$} & \multicolumn{2}{c}{$\begin{array}{c}\text { Standardized } \\
\text { Coefficients }\end{array}$} & \multirow{2}{*}{$\mathrm{t}$} & \multirow{2}{*}{ Sig. } \\
\cline { 3 - 4 } & \multicolumn{1}{c}{ B } & Std. Error & Beta & & \\
\hline 1 & (Constant) & 92.652 & 105.669 & & .877 & .384 \\
& X1 & 27.042 & 16.768 & .149 & 1.613 & .113 \\
X2 & -.026 & .206 & -.010 & -.126 & .900 \\
X3 & -3.405 & .391 & -.816 & -8.711 & .000 \\
X4 & 273.742 & 41.446 & .688 & 6.605 & .000 \\
X5 & 6.741 & 37.751 & .015 & .179 & .859 \\
\hline
\end{tabular}

Keterangan: Constant: X5, X2, X1, X3, X4

Dependent Variable: $\mathrm{Y}$ 


\section{PEMBAHASAN}

Menurut Nurani et al (2008) menjelaskan ketersediaan input produksi merupakan faktor penting agar kegiatan usaha penangkapan tuna dapat berjalan dengan lancar. Input produksi pada perikanan tuna meliputi: (1) ketersediaan teknologi penangkapan (kapal, alat, mesin, dan perlengkapan lainnya); (2) ketersediaan sumberdaya manusia (SDM); (3) ketersediaan modal; (4) ketersediaan perbekalan operasi (BBM, air tawar, es dan umpan); dan (5) ketersediaan informasi. Lebih lanjut dijelaskan berbagai faktor akan berpengaruh terhadap keberhasilan produksi usaha penangkapan tuna diantaranya, (1) ukuran kapal dan mesin; (2) ukuran palka ikan; (3) jumlah mata pancing dan jumlah umpan; (4) jumlah trip; (5) jumlah solar; dan (6) jumlah anak buah kapal (ABK). Sutisna (2007) menyatakan bahwa penyiapan faktor produksi yang baik merupakan penentu utama keberhasilan kegiatan produksi. Pelaku ekonomi termasuk nelayan umumnya akan melakukan kegiatan operasi pada kondisi cuaca baik dan diduga akan membawa hasil yang banyak, sehingga kesiapan faktor produksi menjadi penentu akhir keberhasilan kegiatan produksi.

Hasil analisis regresi berganda menunjukan bahwa penggunaan BBM (X3) dan es balok (X4) sangat berpengaruh nyata terhadap produksi ikan tuna di Kota Ambon. Signifikansinya pengaruh penggunaan BBM dan penggunaan es balok terhadap produksi dikarenakan sifat ikan tuna yang selalu bermigrasi sehingga daerah penangkapan tidak menentu dan jauh. Mengakibatkan es dan BBM merupakan faktor yang penting karena apabila jumlah es dan BBM banyak maka daerah penangkapan bisa lama. Selain itu tujuan operasi penangkapan adalah ikan tuna yang membutuhkan penanganan langsung, sehingga persedian es balok sangat di perlukan guna mempertahankan mutu ikan.

Dari hasil penelitian lapang menunjukan sekali melakukan operasi penangkapan rata-rata nelayan membutuhkan 70 sampai 100 liter bensin dan 2 balok es. Rasio kebutuhan yang begitu besar terhadap BBM (terutama bensin) dan es balok cukup wajar menjadikan kedua faktor produksi ini tidak dapat dile- paskan dari keberhasilan operasi perikanan tuna. Berdasarkan hasil penelitian penggunaan BBM tidak efektif karena sekali melakukan operasi penangkapan sebanyak 100 liter. Ukuran kapal yang kecil dan daerah penangkapan yang tidak terlalu jauh membuat seringkali nelayan kembali dengan BBM yang banyak, ini berpengaruh terhadap banyaknya muatan yang dibawa. Pengurangan jumlah BBM dapat dilakuan untuk pengefisensian jumlah muatan yang dibawa.

Arik (2011) dalam penelitiannya di Teluk Parigi menyatakan faktor produksi yang paling berpengaruh terhadap produktivitas alat tangkap pancing tonda adalah jumlah trip. Sedangkan jumlah $\mathrm{ABK}$, pengalaman ABK dan pengalaman nahkoda juga berpengaruh terhadap hasil produksi walaupun tidak terlalu besar.

Jumlah trip berpengaruh besar dikarenakan tempat pengoperasian alat ini di daerah Samudera Hindia, dimana di perairan ini menjadi jalur ruaya sepanjang tahun dari ikan yang menjadi sasaran penangkapannya. Oleh karena itu kapanpun alat ini dioperasikan akan selalu mungkin untuk mendapatkan ikan yang menjadi sasarannya. Semakin sering frekuensi operasi penangkapan, maka peluang untuk mendapatkan hasil tangkapan semakin besar pula. Untuk nelayan tuna di Kota Ambon, tidak memakai jumlah trip sebagai faktor yang ingin dilihat karena nelayan tuna di Kota Ambon melakukan operasi penangkapan tidak terjadwal. Nelayan melakukan operasi penangkapan sesuai dengan cuaca yang ada. Sehingga faktor jumlah trip tidak dipakai. Berbeda halnya dengan penelitian yang dilakukan Arik nelayan Teluk Prigi melakukan operasi penangkapan 3-5 kali trip tiap bulannya.

Lama trip pengoperasian pancing tonda hanya 1 hari sehingga panjang kapal dan panjang alat tangkap tidak mempengaruhi produksi. Selain itu juga daerah penangkapan ikan tuna yang hanya berada di sekitar perairan Kota Ambon.

Suatu faktor produksi dapat sangat serius mempengaruhi produksi ikan suatu usaha perikanan tangkap, sementara untuk perikanan lainnya mungkin tidak berpengaruh. Menurut Soekartawi (2002), setiap kegiatan produksi mempunyai kebutuhan tersendiri yang unik 
terhadap setiap faktor produksi. Peningkatan kebutuhan akan suatu faktor produksi umumnya tidak bersifat linear terhadap peningkatan hasil dari produksi yang dilakukan. Terkait dengan ini, maka penyiapan faktor produksi perlu dilakukan secara optimal dengan berdasarkan pengalaman dan kalkulasi matematis yang dapat dipercaya. Hasil penelitian Salas et al (2007) di Amerika Latin menunjukkan bahwa strategi produksi dibutuhkan untuk sinkronisasi operasi usaha perikanan dengan perubahan dinamika perairan dan kontrol kebijakan, dimana pelaku perikanan secara periodik mendiskusikan tindakan pengelolaan yang dilakukannya.

Pengembangan perikanan tuna dapat terlaksana dengan mengetahui strategi-strategi apa saja yang harus dilakukan. Dengan memperhatikan faktorfaktor produksi. Strategi-strategi yang dihasilkan dapat dibuat prioritas, mana yang lebih utama guna pengembangan perikanan tuna berbasis masyarakat di Kota Ambon.

\section{KESIMPULAN DAN SARAN}

\subsection{Kesimpulan}

Hasil penelitian menunjukan penggunaan bahan bakar minyak dan penggunaan es balok merupakan hal yang sangat penting dalam mendukung keberhasilan operasi penangkapan ikan tuna. Dengan meningkatnya produksi penangkapan, diharapkan pengembangan perikanan tuna berbasis masyarakat di Kota Ambon dapat dilaksanakan.

\subsection{Saran}

Perlu diperhatikan penggunaan bahan bakar minyak agar lebih efisien dalam pengoperasian pancing tonda.

\section{DAFTAR PUSTAKA}

Arik S. 2011. Strategi Peningkatan Produksi Pada Nelayan Pancing Tonda Di Perairan Teluk Prigi [tesis].
Depok: Program Magister Ilmu Kelautan. Universitas Indonesia. 110 hal.

Departemen Kelautan dan Perikanan. (2004). Ensiklopedia Perikanan. Direktorat Kelembagaan Internasional. Departemen Kelautan dan Perikanan. Jakarta.

Gujarati, Damodar, 1995, Ekonometrika Dasar, Alih Bahasa Ak. Sumarno Zain, Drs., MBA, Erlangga, Jakarta.

Ghozali I, Dr, M.Com, Akt, 2001, Aplikasi Analisis Multivariate dengan Program SPSS, Badan Penerbit Universitas Diponegoro, Semarang.

Khoirul da'i, Ivor L. Labaro dan Aglius T.R. Telleng. 2012. Jurnal Ilmu dan Teknologi Perikanan Tangkap 1(2): 33-37.

Nanlohy CH. Alber, 2013 Evaluasi Alat Tangkap Ikan Pelagis yang Ramah lingkungan di Perairan Maluku dengan Menggunakan Prinsip CCRF. Jurnal Ilmu Hewani Tropika, Volume 2 No.1, Februari 2013: 111.

Nuraini TW, Haluan J, Sudirman S, Ernani L. 2008. Rekayasa Sistem Pengembangan Perikanan Tuna di Perairan Selatan Jawa. Forum Pascasarjana, Vol.31 No.2, April 2008: 79-92.

Sarwono, J. 2006. Analisis data penelitian menggunakan SPSS. Penerbit ANDI. Yogyakarta.

Soekartawi. 2002. Teori Ekonomi Produksi dengan Pokok Bahasan Analisis Fungsi Produksi CobbDouglas. PT. Raja Grafindo Persada. Jakarta.

Sudjana. 2002. Metode Statistik. Tarsito Bandung.

Sutisna, D. H. 2007. Pola Pengembangan Perikanan Tangkap di Pantai Selatan Propinsi Jawa Barat. Disertasi Sekolah Pascasarjana, IPB. Bogor.

Salas, S, R. Chuenpagdee, J.C. Eijo, and A. Charles. 2007. Challenges in the assessment and management of small - scale fisheries in Latin America and the Caribbean. Journal of Fisheries research. Vol 87 (1) : 5-16. 